\title{
Documenting Work and Working Documents: Perspectives from Workplace Studies, CSCW, and Genre Studies
}

\author{
Ciaran B. Trace \\ University of Texas - Austin \\ cbtrace@ischool.utexas.edu
}

\begin{abstract}
This paper examines how organizational documents and the notion of document work is conceptualized and theorized in the fields of Workplace Studies, Computer Supported Cooperative Work, and Genre Studies. In undertaking such an analysis, attention is drawn to the wider historical and intellectual traditions in which these fields emerged, as well as to the notable similarities and differences in their theoretical and conceptual approaches to studying documents and document work. In particular it is acknowledged that studying documents and document work is closely tied to an understanding of the concept and the nature of human action and interaction. In articulating the theoretical and conceptual underpinnings of prior work in these areas, the goal is to provide researchers with an overview of relevant theories and concepts that will help more fully articulate and frame future document research.
\end{abstract}

\section{Introduction}

There is a large body of literature from disparate fields of study (sociology, anthropology, history, information science, education, human computer interaction, history of science, digital and print culture, gender and ethnic studies, rhetoric, composition, and literacy) concerned with the study of how and why everyday (or "non-literary") documents are created and used within social spheres - including organizational and institutional settings, as part of community locales, and in peoples' personal lives. Everyday documents are also a focus of a number of conferences and conference tracks including the Hawaii International Conference on System Sciences Minitrack on Documenting Work and Working Documents, and the annual meeting of the Document Academy (DOCAM).
This paper examines how everyday documents and the notion of document work is conceptualized and theorized in three fields with a vested interest in everyday recorded information, particularly as it exists within an organizational or institutional setting - Workplace Studies, Computer Supported Cooperative Work (CSCW), and Genre Studies. In undertaking this analysis attention is drawn to the wider historical and intellectual traditions in which these fields emerged, as well as to the notable similarities and differences in their theoretical and conceptual approaches to studying documents and document work. In articulating the theoretical and conceptual underpinnings of prior work in these areas, the goal is to provide researchers with an overview of relevant theories and concepts that will help more fully articulate and frame future document research. In particular, an examination of Workplace Studies, CSCW, and Genre Studies in conjunction with theories and theoretical frameworks such as ethnomethodology, symbolic interactionism, distributed cognition theory, activity theory, actornetwork theory and structuration theory underscores the relationship of documents to human actions and activities, highlights documents as instances of organizational communication, and draws attention to the central role that documents play in the mutual intelligibility of action and in how cognition is achieved, as well as the role that documents play in the creation and coordination of social networks.

\section{Workplace studies}

Workplace studies is a subfield of sociology that studies the practical accomplishment of work, the role that technology plays in supporting work and human interaction, and the "critical social processes that surround and embed" these activities [17, pp. 394-395]. The origin of workplace studies has been attributed to a number of developments over the past 
two decades: a widespread critique of conventional models of human-computer interaction (where human action is thought to be "governed by rules, scripts and plans" [25, p. 302]), an increased interest in developing technologies to support collaborative work, and an interest among computer scientists and engineers to identify more robust methods for system requirements in the wake of highly publicized failures in deployment of some computer systems [25]. The origins of workplace studies has also been tied to developments in the field of office automation where the discovery that office tasks could not be modeled as easily as had been assumed, led to a number of in-depth studies in order to better understand the reality of office life [47].

In particular, workplace studies use qualitative methodologies (primarily ethnography) to study how people use digital and non-digital tools, artifacts, and technologies to "accomplish and co-ordinate their day-to-day practical activities" at work [36, p. 12]. Although sociology has tended to neglect the role that tools, artifacts, and technologies play within the workplace, the study of how documents are created and used forms an important part of workplace studies [24]. One reason for this is that digital technologies have profoundly impacted the creation, use and retrieval of textual information and such textual information is now seen as providing a vital resource in the "co-ordination of inter- and intraorganizational activities" [24, p. 309].

A number of theoretical perspectives inform workplace studies (including distributed cognition, course-of-action analysis, and activity theory) and these theoretical frameworks provide unique perspectives on the nature of documents and document work. The most noted of these theoretical frameworks are ethnomethodology and symbolic interactionism. Ethnomethodology was first coined by sociologist Harold Garfinkel in the mid-1950s as a label to capture a "range of phenomena associated with the use of mundane knowledge and reasoning procedures by ordinary members of society" [26, p. 4]. In particular, ethnomethodology studies collaborative sensemaking and how people achieve mutual intelligibility through "constant attention and competent use of shared methods of organizing action" [46, p. 702]. Ethnomethodology has a number of recognized sub-fields including conversation analysis, ethnomethodological studies of the local organization of institutional settings, and the study of specialized work domains and how work is accomplished within these settings [39].

The intellectual roots of ethnomethodology lie in phenomenology, symbolic interactionism, and linguistics. Notable influences on Garfinkel's work include sociologist Talcott Parsons, and philosophers Aron Gurwitsch, Alfred Schütz, and Edmund Husserl $[34,9]$. Schütz's bracketing of the life world for analytic purposes (which involves suspending assumptions about the world every individual takes for granted), is a technique that allows the researcher to place social practices and how they are produced and maintained to the forefront of study [21]. Garfinkel's critique of Parson's theory of action (which embraces the idea of an a priori social world where social order is brought about by external social forces and individuals internalization of society's norms and values) also forms a key element of ethnomethodology [21]. In rejecting the idea of an a priori social world, ethnomethodology focuses instead on how people produce or accomplish social order and how people demonstrate to each other that they recognize a common nature and a "factual reality" to that social world. Ethnomethodology assumes that people achieve this ongoing production of the social world through a variety of ethnomethods [45], and those methods take place via actions such as ordinary conversation and institutional interaction [29].

Ethnomethodology's theory of social order is rooted in concepts such as reflexivity, accounting, indexicality, and the documentary method of interpretation and these concepts are important in shedding light on how documents are perceived and understood within this particular theory of social order. From an ethnomethodological perspective social reality is created reflexively through peoples' thoughts and actions. In particular, the social world is thought of as being "managed, maintained and acted upon through the medium of ordinary description" [26, p. 137]. Our descriptions of the social world, including those embodied in text, are seen as reflexive in that in describing a situation we are also, in effect, reproducing it. This perspective means that documents can be seen not only in the more traditional sense as representations but also as objects that actively constitute aspects of the social world.

In studying the production of social order, ethnomethodology also pays attention to the way that people 'account' for or justify their actions as a way of making sense of the social world around them. In 'accounting' people draw from values and social principles to demonstrate the coherence and rationality of their behavior [21]. The notion of accounts has fundamental implications for our understanding of documents and document work. In Garfinkel's seminal work on clinic records [18] he recognized the ties that existed between records and their associated social systems, in that records were seen as being strongly aligned with the overriding 
priority of the organization. Garfinkel found that records were created, assembled, and used according to "organizationally relevant purposes and routines" $[18$, p. 191], and in a manner that demonstrated the coherence and rationality of the actors involved. In the case of clinic work, this involved assembling and maintaining psychiatric clinic files in such a way that the clinic could be seen as accountable to outside agencies., i.e. that the records within the file could be used to justify a particular course of action between the clinic and the patient. Ethnomethodology also views social situations as indexical in that the meaning of talk and of action (including the use of objects such as documents), are seen as socially situated; their meanings are bound to, and dependent on, peoples' commonly understood knowledge and/or features of the background context in which they occur. Garfinkel [18] found that the interrelationship between records and the social order in which they take part is such that any subsequent "correct reading" [18, p. 201]) of records requires knowledge of the persons, purposes, circumstances, action, and interaction that lie behind the creation of the records in the first instance.

If documents can only be understood in context, a way this understanding can be achieved is through what ethnomethodology calls the "documentary method of interpretation." The documentary method of interpretation treats any action as a 'document' or expression of a presupposed underlying pattern drawn from peoples' common knowledge and experience [18]. Actions and patterns are also selfreferential - not only is the underlying pattern derived from the action, but the action is also understood in relationship to the underlying pattern to which it is said to refer. In applying the documentary method of interpretation to methods and actions that surround texts, researchers such as Howard Zimmerman [59] have shown that people treat documents as expressions of underlying patterns, and these patterns in turn can be used by people to infer meaning and motivation in others [17]. In Zimmerman's study of record-keeping and the intake process in a public welfare agency, the way that documents are read and viewed as part of the process of applying for assistance can be seen as an expression of an underlying notion on the part of agency caseworkers that applicants should not be viewed as trustworthy.

While the effect of ethnomethodology on workplace studies is profound, nowhere is this more keenly felt then in Suchman's work, Plans and Situated Actions [54]. In this book Suchman questioned the Artificial Intelligence approach to the design of computer systems in which human action or behavior is equated with the execution of mental plans. In its stead, Suchman offers a framework that recognizes human activity as situated; where action is not determined by plans but where plans themselves are located within a wider system of ongoing practical activity. According to Suchman, the organization of situated action is "an emergent property of moment-by-moment interactions between actors, and between actors and the environments of their action" [54, p. 179]. Suchman's framework views documents not as actions per se, but as representations of situated actions, produced during or subsequent to action, and representative of the interests of those who produced them. As representations, documents are potential resources for "both the author(s) and for others who later become engaged in a similar action" [2].

Taking either a conceptual or a more pragmatic design perspective, other ethnomethodologically informed workplace studies have examined the role that various tools and technologies (digital and nondigital) play in workplace practices, conduct, and interaction. In seeking to study the use of technology in the workplace, this research has shed particular light on the extent to which the technical transformation of paper documents "resonates with indigenous work practices and procedures" [24, $\mathrm{p}$. 302]. In Heath and Luff's [25] play on Garfinkel's seminal work on clinic records, the authors examined why general practitioners in the United Kingdom persisted in using paper based medical records despite the advantages of computer based systems. Echoing Garfinkel, their work is premised on the notion that the reading and writing of the medical record "rests on a body of socially organized practices and conventions which inform both the production and the intelligibility of the records" [25, p. 33]. Their findings suggest that these practices, conventions, and indigenous reasoning were poorly supported by the introduction of a new computer system. In particular, the computerization of clinic records led to a disruption of the internal organization of medical record entries and to a disruption of the order of the medical entries in relation to each other. This in turn interfered with the process of the in-situ writing and reading of the medical record.

The notion of the resilience of paper is also reflected in an interest in workplace studies in the concept of "affordances;" a notion attributed to ecological psychologist James J. Gibson [49]. The concept of affordances refers to the fact that the properties of objects are said to "determine the possibilities of action" [49, p. 17]. In The Myth of the Paperless Office, Sellen and Harper use the concept of affordances to investigate the ways in which documents support office activities, with a particular 
focus on how the difference in affordances between paper and digital technologies make possible different workplace functions. The resilience of paper, for example, is said to be tied to the fact that many organizational work practices developed in concert with the use of paper, and to the fact that certain physical properties of paper documents do a good job of supporting workplace activities including authoring and reviewing work, collaborative work, and organizational communication. The affordances of digital technologies, on the other hand, are linked to support for access, search, and storage, as well as the ability to link, modify and update content.

Symbolic interactionism, and in particular Anselm Strauss' work on social worlds and his theory of action, have also had a profound impact on workplace studies and on our understanding of documents and document work. According to Strauss, social worlds are communities with shared commitments to particular activities, the doing of which involves technology of different kinds (technology being defined as "inherited or innovative modes of carrying out the social world's activities") [51, p. 122]. Strauss believed that peoples' external and internal worlds were created and re-created through interaction. The importance of this fact is that it means that people must find a way to work together in order to get things done [53]. The circulation of documents among members ("keeping each conscious of being a member and aware of what others are up to") is seen to play a key role in holding these social worlds together [7].

Another important element of Strauss' work as it relates specifically to documents and document work is the concept of "articulation work." As an element of the articulation process, articulation work refers to the idea that cooperative work involves the meshing of tasks, efforts, and actors in order to get work done [52]. Artifacts, including documents, play a central role in coordinating and handling that articulation work. However, the taken-for-granted nature of articulation work and the work of documents in that articulation process, means that the role of documents in "keeping the work practice together" [6, p. 201] may only be noticed when the process breaks down, such as in the case of an organization's move from paper to digital documents. In such a scenario it has been found that when paper gives way to digital systems the role that documents play as a shared resource, essential for people to carry out work practices, can be interrupted. As a result of that interruption the need for articulation work is actually enhanced because of the resulting increase in complexity in work organization [6].

\section{Computer supported cooperative work}

The term Computer Supported Cooperative Work was coined at a workshop organized in 1984 by Irene Greif of MIT and Paul Cashman of Digital Equipment Corporation at which researchers from a number of disciplines came together to explore the role of technology in the work environment $[10,20$, 42]. As a multidisciplinary field, (and one that is described as in "an advanced state of fragmentation" [47, p. 223]), CSCW research follows a number of different paths. A technical strand of research within $\mathrm{CSCW}$ is seen as firmly rooted within the more senior research field of Computer-Mediated Communication [47]. In this worldview, $\mathrm{CSCW}$ is seen as a design oriented field that studies "the use of computing and communication technologies to support group and organizational activity" [43, p. 1433]. This research stream focuses primarily on the study of technology and tools, including the different types of applications that support collaborative work. A social strand of research emphasizes that $\mathrm{CSCW}$ is "neither solely a tool or technology business, not just a new way to study computer impact on the work place" [38]. In its place, emphasis is put on "the distinctive qualities of co-operative work processes, and on questions of design: how to mould computer technology to fit into and support these work processes" [38]. This notion of CSCW encompasses the body of workplace studies and associated theoretical frameworks and concepts described earlier. $\mathrm{CSCW}$ has embraced the study of organizational documents and document work as researchers have come to see that "material work settings and the artifacts that populate them play a crucial role in the seamless and effective coordination and alignment of cooperative work" [48, p. 257].

If ethnomethodology and Strauss and Suchman's theories of action have all influenced CSCW [14] there are a number of other theoretical approaches and constructs which have a direct influence on how documents are conceptualized and understood within this sphere of research. These include distributed cognition theory, activity theory, actor-network theory, the coordination theory of Thomas W. Malone and Kevin Crowston, and structuration theory [43], the first three of which will be discussed here. The increased interest in these conceptual frameworks has been partly attributed to the fact that these theories, in contrast to areas such as social psychology, are "seen to accord artifacts and their use a crucial role in human action and interaction" $[48, \mathrm{p}$. 258]. 
Activity theory and distributed cognition theory are cognitively based theories which share a commitment to ethnographically collected data and method [23]. They differ in their chosen unit of analysis and in their understanding of the material world, in particular their understanding of the relationship between human activities and the artifacts, including documents, which humans use. Activity theory has its historical roots in classical German philosophy, the writings of Marx and Engels, and in the work of Soviet psychologists Vygotsky, Leont'ev, and Luria [30, 15]. Essential to activity theory is the idea that "the development of thoughts and cognitive activity requires social interaction and exchange with a physical environment" [15, p. 155]. In order to explore human consciousness, the chosen unit of analysis is the activity (defined as "a subject's interaction with his or her surroundings," [15, p. 155]). Activities, while shared, are also driven by an individual's motive or goal [41]. In this approach, interaction is not only seen as a social process but one which is also surrounded by historical and cultural contexts. Engeström [13] added to the classic model of activity theory by introducing the idea of an activity system, a system comprised of the additional components of community, rules, and division of labor. This development allows for the examination of systems of activity at a more macro level, an approach particularly helpful in studying organizations.

More specifically, human interaction (an activity) is said to be comprised of an alignment of subjects (a person or group engaged in some activity), an object or objective (something held by the subject that motivates the activity), actions (tasks), and operations (the way an activity is carried out) [41]. A key facet of activities and activity systems are material and/or conceptual artifacts (examples of which include "instruments, signs, procedures, machines, methods, laws, forms of work organization") [30, pp. 26-27]. As a form of tool or artifact, documents are seen as having a mediating role, acting as a go-between between elements of the activity system including the subject, the goals and actions (objects) that drive an activity forward [30], and the community. Documents therefore mediate the actions of individual subjects as well as mediating between the actions of members of the community. As a type of artifact, activity theory views documents as oriented to activity (over time documents develop and are taken up because of their very ability to mediate activities) and as physical artifacts that can both transform and constrain the objects of that activity. Activity theory also views documents as being shaped by the wider socio-historical context of which they are a part.

As a theoretical framework, distributed cognition began life in the mid-1980s through the work of cognitive psychologist and anthropologist, Edwin Hutchins. In distributed cognition the unit of analysis is a cognitive system "composed of individuals and the artifacts that they use" [41, pp. 38-39]. Unlike traditional views of cognition (where cognitive activity is viewed solely as an activity that happens within the brain), distributed cognition theory sees cognitive activity as distributed across internal individual minds and external cognitive artifacts and structures, as well as across members of social groups [28]. Similar to activity theory, cognitive systems are seen as goal oriented and that goal is understood and analyzed at the system rather than at the individual level [41]. Hutchins' field studies of socio-technical systems, including a study of cognition in an airline cockpit [27] show that an understanding of distributed cognitive systems involves understanding how cognition is achieved through the coordination of internal and external representations of information or knowledge. These representations are in turn shared and transformed through a series of representational media (these media can be internal, such as a person's tacit knowledge, or part of the external environment, as in the case of tools such as instruments and artifacts). As part of this theoretical framework documents can be seen as an example of a representation of knowledge external to an individual that takes the form of a physical "cognitive artifact". Distributed cognition eschews the traditional notion that such tools or cognitive artifacts simply serve to make cognitive tasks or activities easier or more efficient [35]. In-its-place, the creation and use of documents is viewed as an integral part of the larger cognitive system made up of the cognitive properties of groups of people, the affordances and constraints provided by the environment around them, and the cognitive artifacts or tools people use to accomplish and coordinate tasks $[35,55]$.

Despite according artifacts a prominent role in action and interaction both activity theory and Hutchins' work in distributed cognition have been criticized for their role in what is seen as the "dematerialization of the concept of artifacts"; a criticism leveled at these theories for failing to fully distinguish between mental and physical tools and artifacts [48]. In an attempt to rectify this perceived shortcoming, Schmidt and Wagner have proffered the concept of "coordinative artifacts," arguing that artifacts can serve a coordinative function because of their very materiality and their representational role, not in spite of it [48, p. 271]. 
Drawing from ethnomethodology, actor-network theory originated in the 1970s and 1980s in the area of sociology and science and technology studies through the work of Bruno Latour, Michel Callon, and John Law as a way of studying scientists and engineers in action. In its early days, actor-network theory looked at how scientists got buy-in from others for what scientists regarded as scientific facts, as well as looking at how scientists acquired the "power and resources" to go about their work [56, p. 13]. Nowadays, actor-network theory is concerned with the nature of power and social order more generally and in particular how social structure comes into being [56]. Similar to ethnomethodology, actor-network theory is not interested in "why" questions so much as it is interested in "how" questions - how actor networks get formed, are held together, or break apart, and how power operates within a heterogeneous network of people and things $[32,8]$. Social networks are seen to be created by heterogeneous means - by humans acting in concert with other non-human actors or actants (technical, textual - such as documents -, or naturally occurring) to facilitate a specific goal. As such, actor-network theory "does not celebrate the idea that there is difference in kind between people on the one hand, and objects on the other" [33, p. 857], instead people and material artifacts are put on an equal conceptual and theoretical footing.

For CSCW and the study of documents, an important concept in actor-network theory is that of "inscriptions." Inscriptions are a form of intermediary in actor-network theory, an intermediary being an actant that "translates between participants in such a way that their interaction can be coordinated or controlled" [56, p. 14]. Latour [31] has also added to the work on inscriptions through his concept of "immutable mobiles" - inscriptions that are highly standardized, mobile, presentable and combinable in order to facilitate communication among groups. In the world of documents and document work, immutable mobiles are texts such as standardized forms. Within actor-network theory, documents can therefore be seen as main constituents of the social world; a means of enhancing and perpetuating the interests of an actor and as a way in which actors can align themselves with a network. Documents, as inscriptions can also "facilitate action at a distance, link one's work to others', persuade the reader, and enroll others to accept the picture built by the text, thereby garnering resources to continue" [56, p. 15]. The writings of Latour, Callon and Law, with its emphasis on cooperation and the notion of translation, has also been extended through the work of Susan Leigh Star and James Greiesmer on "boundary objects" [50]. Boundary objects, of which documents are but one instance, are objects that are capable of acting as an interface between different communities. These objects are said to be flexible enough to have different meanings depending on the social world in which they reside but a structure "common enough to more than one world to make them recognizable, a means of translation" [50, $\mathrm{p}$. 393]. The creation and management of boundary objects such as documents is seen to be a "key process in developing and maintaining coherence across intersecting social worlds" [50, p. 393].

\section{Genre studies}

The concept of "genre" (including oral and written forms) has a long tradition in the fields of rhetorical and literary analysis [58], dating back at least to the time of Aristotle [12]. From earliest times, particular emphasis was placed on the study of literary genres as a type of discourse and such genre analysis served as a "practical way to organize and index literary works, as well as a way of entailing rules to literary creation" [1]. Since the mid-1980s the area of genre studies has been transformed by approaches that marry humanities and social science perspectives and include the study of the "linguistic, sociological, and psychological assumptions underlying and shaping these text-types" [4, p. 335]. This work has expanded the notion of genre beyond literary types to include genres used in everyday settings and within academic and professional disciplines. Scholars in a number of research fields have helped to shape this work, including researchers in functional and applied linguistics, literature, communication studies, education, and rhetoric and composition studies $[4,11]$.

This new stream of research can be divided into two main approaches [37] - one of which draws from a linguistic and the other from a rhetorical tradition. These traditions give us a richer understanding of documents as instances of organizational communication and of the relationship of organizational documents to the larger social context in which they reside. Drawing from linguistic theory, the first approach focuses primarily on the textual analysis of genres (language and the structure of text) with the goal of translating findings into models for education and the teaching of literacy. Such research is often associated with the "Sydney School" (so called because of its association with Sydney University's Department of Linguistics). The Sydney School takes a particular interest in the work of linguist Michael Halliday. For Halliday, oral and 
written language plays an important role in how people are socialized into a community and in how people perform meaningful actions within recurring situations. Within these recurring situations, people are said to develop typified ways of interacting. Halliday views language as consisting of text (what it is that people say or write), situation (the environment in which the text comes to life), the register (semantic variety of types of which a text is an instance), code (which controls the semantic styles available to people in a given context), linguistic system, and a social structure [22]. Language variation is seen to be linked to the social context in which language is used. From this understanding comes Halliday's theory of registers - a theory that links texts to situation. Three variables are said to combine to form the register of a text - field (what language talks about), tenor (the participants of an activity, their role in the activity and their relationship to each other vis-à-vis issues such as power and status), and mode (the way in which language takes part in the activity, such as whether the language is in written or spoken form). The concepts of field, tenor, and mode also have corresponding concepts, called metafunctions, at the linguistic level [22]. However, despite the obvious importance of the social and situational aspects of communication, the use of Halliday's work to study organizational documents ultimately leads to a greater emphasis being placed on elucidating textual features through linguistic analysis.

A second approach includes researchers in the "New Rhetoric" or "Rhetorical Genre Studies" movement in the United States. A number of theoretical approaches are said to underlie this current thinking about the notion of genre including a focus on the rhetorical dimensions of language use, social constructionism, rhetorical versions of rationality, and speech act theory (where language is viewed, among other things, as a mode of action) [16]. Rhetorical genre studies have also been explicitly linked to the rhetorical, phenomenological and sociological traditions [5]. A key element of this approach is the emphasis placed on the relationship of the text to the broader social context in which genres reside [37]. In studying genres, the notion of context is said to require an understanding of the "complex social, cultural, institutional and disciplinary factors" at play as people produce, learn and interact with language through different kinds of writing [16, p. 2]. Genres are also seen to play a role in how people "experience, co-construct, and enact social practices and sites of activity" [5, p. 59]. Unlike Halliday's approach where genres are viewed as relatively stable forms, from this viewpoint genres are seen as "relatively unstable, or "stabilized-fornow," rhetorical forms that must be studied in their context of use and in relation to the goals that they are used to accomplish in a specific discourse community" [37, p. 286]. This focus on the study of genres as "forms of situated cognition, social action, and social reproduction" is said to come at the expense of the more precise linguistic analysis characteristic of systemic functional genre research $[5$, p. 60].

Mikhail Bakhtin's study of the nature, form and use of language and his study of the relationship of language to human activity have been particularly influential for research adopting a more sociocontextual perspective. For Bakhtin, human activity involves the use of language and language is brought to life in the form of individual concrete utterances (oral and written) [3]. The "specific conditions and goals" of areas of human activity are said to be reflected in the content and linguistic style, but above all through the compositional structure, of both oral and written utterances [3, p. 60]. Each sphere of activity in which language is used is said to develop its own fairly stable types of utterances, called speech genres, and these repertoires of genres are said to "differentiate and grow as the particular sphere develops and becomes more complex" [3, p. $60]$. There is also a horizontal and a vertical axis of genre relations in Bakhtin's work [5]. The horizontal axis relates to the "dialogic nature" of genres, in that, within the communication process, one genre is seen as a response to another [5, p. 25]. Bakhtin also distinguishes between primary (simple) and secondary (complex) forms, primary genres being seen as genres used in day-to-day communicative activities, and as the building blocks of secondary genres that "arise in more complex and comparatively highly developed and organized cultural communication" $[3$, p. 62]. Genre forms are also seen as flexible enough that they can reflect individual style, although this is not necessarily the case with genres requiring a standardized form (including many organizational documents) [3]. Another particularly influential figure in rhetorical genre studies is Carolyn Miller, whose ethnomethodologically informed work has introduced the notion of genres as typified forms of social action [40]. In marrying prior research in rhetorical criticism with phenomenological understandings from Schütz about intentionality, the life world, and the role of people's stock of knowledge in helping mediate people's perceptions of things, such a framework views genres as "socially derived, intersubjective, rhetorical typifications that help us recognize and act within recurrent situations" [5, p. 69]. 
Although the theoretical perspectives just described provide unique frameworks in which organizational documents as written genres can be studied, there is also a body of research that has specifically examined document genres in organizational contexts. Such studies utilize perspectives from both genre approaches but are also particularly informed by activity theory (discussed earlier in this paper) and Anthony Giddens' structuration theory [19]. Drawing together strands from structural functionalism and phenomenological and hermeneutic traditions, structuration theory holds that human action happens within a pre-existing social structure that is governed by a set of social rules or norms. This relationship between human agency and social structure is seen as a duality - there is a pre-existing social structure that makes social action possible but social action also creates or modifies those very structures. This interdependent relationship is also seen to evolve over space and time. Drawing from structuration theory and notions of genre from existing rhetorical theory, JoAnne Yates and Wanda J. Orlikowski have examined the intersection of genre, human communication, and organizational action, and in doing so introduced the idea of "genres of organizational communication". Specifically, an organizational genre (such as a memo or a report) is seen as a "typified communicative action," with a common subject and common formal features, which is called upon in response to a recurrent situation. According to Yates and Orlikowski, people draw from tacit or explicit knowledge of social rules to create organizational genres, and in doing so can constitute, legitimize and modify these genres [57, 44]. Orlikowski and Yates have also introduced the term "genre repertoire" as a way of studying how sets of genres are enacted in group contexts [44], and in the process have added to the growing body of literature on how researchers discuss assemblages of documents.

\section{Discussion and conclusion}

The historical and intellectual context of these three fields of study, as well as their disparate and at times overlapping areas of interest, come together to form rich theoretical traditions from which we can better understand the nature of documents. Drawing from a multitude of theories and perspectives, this research uncovers important understandings about the relationship between documents and human action and interaction. There is agreement that human action cannot be understood in isolation from context. However, what that context means differs in part due to the fact that theories have differing units of analysis (whether it is the mutual intelligibility of action, action itself, an activity, a cognitive system, social networks, or the relationship of language to human activity). These theories are at variance in their belief in an a priori social world and the degree to which human action and activity is seen as constituted in the moment rather than being "descriptive of enduring patterns of behavior across situations" [41, p. 36]. These theories take sides in that age old debate over what determines people's behavior - human agency and/or social structure. These theories even diverge in the extent to which people and things are seen as conceptually equivalent.

However, the result of an engagement with these differences and similarities is the opportunity to explore the nature of documents and document work from a multitude of perspectives. The combination of workplace studies and ethnomethodology allows us to study how social practices are produced and maintained in these social settings. Ethnomethodology is particularly attuned to the role that organizational documents play in describing, representing and constituting the social world. Ethnomethodology speaks to the notion that reading, writing, and interpreting of such documents relies on a body of socially organized practices and conventions. Ethnomethodology also pays attention to the role that documents play as expressions of underlying patterns that people use to infer motive in the behavior of others. The juxtaposition of workplace studies and symbolic interactionism emphasizes the role that documents play in coordinating and handling the meshing of organizational tasks, efforts, and actors in order to get work done. However, the fact that documents support this critical aspect of organizational life is often only noticed when the process is disrupted.

The focus of CSCW is firmly on understanding the distinctive qualities of co-operative work processes and how technology can be used to support cooperative work. CSCW is interested in documents from the perspective of understanding the role that documents play in coordinating and aligning such cooperative work. In combining $\mathrm{CSCW}$ with activity theory we get a view of documents as oriented to activity, where over time documents develop and are taken up because of their very ability to mediate the action of individuals as well as mediating between the actions of members of the community. As representations of knowledge external to an individual, distributed cognition affords documents a central role in how cognition is achieved. In actornetwork theory humans are seen to work in concert 
with documents to create social networks. In particular, documents are seen as both a form of intermediary and a way of coordinating and controlling interaction. The various traditions in genre studies give us a richer understanding of documents as instances of organizational communication. These traditions also allow us to drill down into the internal characteristics of these documents as well as to understand the relationship of organizational documents to the larger social context in which they reside.

Finally, not only do these fields of research and their associated theories allow us to study the role of documents in human action and interaction from many angles, they also endow us with a rich language in which to explore this world. The notion of 'affordances' allows us to investigate the relationship between properties of documents and the possibilities for action. The notion of 'immutable mobiles' speaks to the role of documents in facilitating communication among groups. And the notion of 'boundary objects' enriches our exploration of the ways that documents help maintain coherence across and between social worlds.

\section{References}

[1] P. Antunes, C. J. Costa, and J. A. Pino, "The Use of Genre Analysis in the Design of Electronic Meeting Systems", IRInformation Research 11 (3), April 2006.

[2] M. Aronson, D. Bell, and D. Vermeer, "Coordination of Technological Practice and Representations at the Boundaries", in M. B. Schiffer (ed.) Anthropological Perspectives on Technology, University of New Mexico Press, Albuquerque, N.M., 2001, pp. 179-191.

[3] M. Bakhtin, "The Problem of Speech Genres", in C. Emerson and M. Holquist (eds.), Speech Genres and Other Late Essays, University of Texas Press, Austin, TX, 1986, pp. 60-102.

[4] A. Bawarshi, "The Genre Function", College English 62 (3), 2000, pp. 335-360.

[5] A. S. Bawarshi and M. J. Reiff, Genre: An Introduction to History, Theory, Research, and Pedagogy, Parlor Press, Indiana, 2010.

[6] K. Braa and T. I. Sandahl, "Introducing Digital Documents in Work Practices - Challenges and Perspectives", Group Decision and Negotiation (9), 2000, pp.189-203.

[7] J. S. Brown and P. Duguid, "The Social Life of Documents", First Monday 1 (1), May 1996.

[8] M. Callon, "Some Elements of a Sociology of Translation", in J. Law (ed.), Power, Action, Belief: A New Sociology of Knowledge?, Routledge \& Kegan Paul, London, 1986, pp. 196-233.

[9] A. Coulon, Ethnomethodology, Sage Publications, Thousand Oaks, 1995.

[10] A. Crabtree, T. Rodden and S. Benford, "Moving with the Times: IT Research and the Boundaries of CSCW",
Computer Supported Cooperative Work 14 (3), 2005, pp. 217-251.

[11] A. J. Devitt, "Generalizing about Genre: New Conceptions of an Old Concept", College Composition and Communication 44 (4), 1993, pp. 573-586.

[12] A. J. Devitt, "Integrating Rhetorical and Literary Theories of Genre", College English 62 (6), July 2000, pp. 696-718.

[13] Y. Engeström, "Innovative Learning in Work Teams: Analyzing Cycles of Knowledge Creation in Practice", in Y. Engestrom et al (eds.), Perspectives on Activity Theory, Cambridge University Press, Cambridge, 1999, pp. 377406.

[14] G. Fitzpatrick, W. J. Tolone, S. M. Kaplan, "Work, Locales and Distributed Social Worlds", in H. Marmolin, Y. Sundblad, and K. Schmidt (eds.), Proceedings of the Fourth European Conference on Computer Supported Cooperative Work, Kluwer Academic Publishers, Stockholm, Sweden, September 10-14, 1995, pp. 1-16.

[15] M. Fjeld, K. Lauche, M. Bichsel, F. Voorhorst, H. Krueger, and M. Rauterberg, "Physical and Virtual Tools: Activity Theory Applied to the Design of Groupware", Computer Supported Cooperative Work 11, Kluwer Academic Publishers, Netherlands, 2002, pp. 153-180.

[16] A. Freedman and P. Medway, "Locating Genre Studies: Antecedents and Prospects", in A. Freedman and P. Medway (eds.), Genre and the New Rhetoric, Taylor \& Francis, London, 2003, pp 1-22.

[17] A. C. Garcia, M. E. Dawes, M. L. Kohne, F. M. Miller, and S. F. Groschwitz, "Workplace Studies and Technological Change", Annual Review of Information Science \& Technology (40), 2006, pp. 393-437.

[18] H. Garfinkel, Studies in Ethnomethodology, Polity Press, Cambridge, 1999.

[19] A. Giddens, The Constitution of Society: Outline of the Theory of Structuration, University of California Press, Berkeley, 1984.

[20] J. Grudin, "Computer Supported Cooperative Work: History and Focus", IEEE Computer 27 (5), May 1994, pp.19-26.

[21] J. F. Gubrium and J. A. Holstein, "Analyzing Interpretive Practice", in N. K. Denzin and Y. S. Lincoln (eds.), Handbook of Qualitative Research, Second Edition, Sage, Thousand Oaks, 2000, pp. 487-508.

[22] M. Halliday, "Language as Social Semiotic", in J. Maybin (ed.), Language and Literacy in Social Practice, Multilingual Matters Ltd., Clevedon, Avon, England, 2003, pp. 23-43.

[23] C. A. Halverson, "Activity Theory and Distributed Cognition: Or What Does CSCW Need to DO with Theories?", Computer Supported Cooperative Work 11 (12), 2002, pp. 243-267.

[24] C. Heath, H. Knoblauch, and P. Luff. "Technology and Social Interaction: the Emergence of "Workplace Studies'”, British Journal of Sociology 51 (2), June 2000, pp. 299-320.

[25] C. Heath and P. Luff. Technology in Action, Cambridge University Press, Cambridge, UK, 2000.

[26] J. Heritage. Garfinkel and Ethnomethodology, Polity Press, Cambridge [Cambridgeshire], 1996. 
[27] E. Hutchins, "How a Cockpit Remembers its Speed", Cognitive Science 19, 1995, pp. 265-288.

[28] E. Hutchins, "Distributed Cognition", in W. Kintsch (ed.), International Encyclopedia of the Social \& Behavioral Sciences, 2001, pp. 2068-2072.

[29] I. Koskinen, "Workplace Studies: An Ethnomethodological Approach to CSCW', Plenary speech at Nordic Interactive Meeting in Helsinki, March 31, 2000.

[30] K. Kuutti, "Activity Theory as a Potential Framework for Human-Computer Interaction Research", in B. A. Nardi (ed.), Context and Consciousness. Activity Theory and Human-Computer Interaction, MIT Press, Cambridge, 1996, pp. 17-44.

[31] B. Latour, Science in Action, Harvard University Press, Cambridge, Mass., 1987.

[32] B. Latour, Reassembling the Social: An Introduction to Actor-Network-Theory, Oxford University Press, Oxford, 2005.

[33] J. Law, "Notes on the Theory of the Actor-Network: Ordering, Strategy, and Heterogeneity" in Warwick Organizational Behavior Staff (ed.) Organizational Studies: Critical Perspectives on Business and Management, Routledge, London, 2001, pp. 853-868.

[34] K. Leiter, A Primer on Ethnomethodology, Oxford University Press, New York, 1980.

[35] Z. Lieu, N. Nersessian, and J. Stasko, "Distributed Cognition as a Theoretical Framework for Information Visualization", IEEE Transactions on Visualization and Computer Graphics 14 (6), 2008, pp. 1173-1180.

[36] P. Luff, J. Hindmarsh, C. Heath (eds), Workplace Studies: Recovering Work Practice and Informing System Design, Cambridge University Press, Cambridge, UK, 2000.

[37] M. J. Luzón, "Genre Analysis in Technical Communication", IEEE Transactions on Professional Communication 48 (3), September 2005, pp. 285-295.

[38] K. Lyytinen, "Computer Supported Co-operative Work (CSCW) - Issues and Challenges," Technical report, Department of Computer Science, University of Jyväskylä, Finland, 1989.

[39] D. W. Maynard, and S. E. Clayman, "The Diversity of Ethnomethodology", Annual Review of Sociology (17), 1991, pp. 385-418.

[40] C. Miller, "Genre as Social Action", Quarterly Journal of Speech (70), 1984, pp. 151-67.

[41] B. A. Nardi, "Studying Context: A Comparison of Activity Theory, Situated Action Models, and Distributed Cognition," in Context and Consciousness: Activity Theory and Human-Computer Interaction, MIT Press, Cambridge, MA, 1996, pp. 35-52.

[42] M. Nilsson, "Workplace Studies Revisited", Proceedings of the 28th Information Systems Research Seminar in Scandinavia (IRIS 28) Kristiansand, Norway, Agder University College, 2005.

[43] G. M. Olson and J. S. Olson, "Research on Computer Supported Cooperative Work", in M. G. Helander, T. K. Landauer, and P. V. Prabhu (eds)., Handbook of Humancomputer Interaction, Second Edition, Elsevier, Amsterdam and NY, 1997, pp.1433-1456.
[44] W. J. Orlikowski and J. Yates, "Genre Repertoire: Norms and Forms for Work and Interaction", MIT Sloan School Working Paper \#3671-94, 1994.

[45] G. C. F. Payne, "Making a Lesson Happen: an Ethnomethodological Analysis", in M. Hammersley and P. Woods (eds.), The Process of Schooling: A Sociological Reader, Routledge and Kegan Paul Ltd., London, 1976, pp. 33-40.

[46] A. W. Rawls, "Harold Garfinkel, Ethnomethodology, and Workplace Studies", Organization Studies 29 (5), 2008, pp. 701-732.

[47] K. Schmidt, "Divided by a Common Acronym: On the Fragmentation of CSCW", in I. Wagner et al. (eds.), ECSCW 2009: Proceedings of the 11th European Conference on Computer-Supported Cooperative Work, 711 September 2009, Vienna, Austria (Springer, London, 2009), pp. 223-242.

[48] K. Schmidt and I. Wagner, "Coordinative Artifacts in Architectural Practice", in M. Blay-Fornarino, A. M. PinnaDery, K. Schmidt and P. Zaraté (eds), Cooperative Systems Design: A Challenge of the Mobility Age, IOS Press, Amsterdam, 2002, pp. 257-274.

[49] A. J. Sellen and R. Harper, The Myth of the Paperless Office, MIT Press, Cambridge, 2002.

[50] S. L. Star and J. R. Griesemer, "Institutional Ecology, 'Translations' and Boundary Objects: Amateurs and Professionals in Berkeley's Museum of Vertebrate Zoology, 1907-39”, Social Studies of Science 19 (3), 1989, pp. 387-420.

[51] A. Strauss, "A Social World Perspective," Studies in Symbolic Interaction, 1(1), 1978, pp. 119-128.

[52] A. L. Strauss. Creating Sociological Awareness: Collective Images and Symbolic Representations, Transaction Publishers, New Brunswick (U.S.A.), 1991.

[53] A. L. Strauss, Continual Permutations of Action, Aldine de Gruyter, New York, 1993.

[54] L. A. Suchman. Plans and Situated Actions: The Problem of Human-Machine Communication, Cambridge University Press, Cambridge, 1987.

[55] T. Susi, J. Lindblom, and T. Ziemke, "Beyond the Bounds of Cognition", in R. Alterman \& D. Kirsh (eds.) Proceedings of the 25th Annual Conference of the Cognitive Science Society, Lawrence Erlbaum, Mahwah, NJ, 2003, pp. 1134-1139.

[56] N. A. Van House, "Science and Technology Studies and Information Studies", Annual Review of Information Science \& Technology (38), 2004, pp. 1-86.

[57] J. Yates and W. J. Orlikowski, "Genres of Organizational Communication: A Structurational Approach to Studying Communication and Media", Academy of Management Review 17 (2), April 1992, pp. 299-326.

[58] T. Yoshioka, G. Herman, J. Yates and W. Orlikowski, "Genre Taxonomy: A Knowledge Repository of Communicative Actions", ACM Transactions on Information Systems 19 (4), October 2001, pp. 431-456.

[59] D. H. Zimmerman, "Record-Keeping and the Intake Process in a Public Welfare Agency", in S. Wheeler (ed.), On Record: Files and Dossiers in American Life, Russell Sage Foundation, New York, 1969, pp. 319-354. 